Economía, Sociedad y Territorio, vol. viII, núm. 28, 2008, 1067-1078

\title{
La ciudad de México: entre la vulnerabilidad ambiental y la sustentabilidad
}

\section{Mexico City: between environmental vulnerability and sustainability}

\author{
Ezcurra, Exequiel, Marisa Mazari, Irene Pisanty y Adrián \\ Guillermo Aguilar (2006), La cuenca de México. Aspectos \\ AMBIENTALES CRÍTICOS Y SUSTENTABILIDAD, FONDO DE CULTURA \\ ECONÓMICA, MÉXICO, 286 PP., ISBN 968-16-7558-4.
}

Los procesos de metropolización de la ciudad de México han derivado en la construcción de un conglomerado urbano con enorme vulnerabilidad, el cual se sostiene sobre dos tipos de incompatibilidades: la sujeción de los ecosistemas a su alrededor y la centralización económica, ambas anacrónicas. Para entender las formas, causas y consecuencias de la degradación ambiental ocasionada por la megalópolis, se tradujo al español el libro La cuenca de México. El libro editado en inglés en el año 2000, y que el FCE publicó en 2006, representa un acontecimiento que aunque aparentemente tardío, es de celebrarse dada la relevancia de este tema estratégico para la seguridad nacional y pública del país; y ni qué decir en relación con las implicaciones que conlleva en materia de políticas ambientales regionales, así como de desarrollo urbano sustentable, que son muchas.

En la investigación realizada se establece un postulado central: el rumbo, las condiciones y los factores del proceso de urbanización está determinado por el estado de la cuenca de México, el cual ha modificado drásticamente la intervención humana, sobre todo recientemente. Asimismo, se explican la historia, la situación, los cambios recientes y las fuerzas del cambio ambiental en la región para entender los riesgos presentes y así poder plantear las respuestas a este problema.

Además de que es la continuación de brillantes publicaciones de los autores, el libro es producto de acuciosas investigaciones que no escatimaron esfuerzos intelectuales para lograr su cometido, el cual se traduce en un extraordinario servicio prestado a las comunidades ambientalistas del país y del mundo (principal- 
mente de las megalópolis de los países en desarrollo), así como a científicos y estudiosos del tema.

De esta manera se escudriñaron innumerables fuentes bibliográficas, imágenes satelitales, estadísticas, etc., para indagar hechos que resultaron indispensables para construir esta gran obra, por su contenido y trascendencia, lo que permitió primero hacer un diagnóstico de la degradación ambiental de la ciudad de México y después proponer algunas soluciones. Aunque pequeño en extensión (286 pp.), este libro aborda ampliamente un problema de la complejidad que representa la Zona Metropolitana de la ciudad de México (ZMCM), cuyos habitantes en el 2006 eran aproximadamente (según el Gobierno del Distrito Federal) 20 millones (considerando sólo al D. F., en una extensión de 1,400 $\mathrm{km}^{2}$ habitan unos 8 millones).

La ZMCM es parte integrante de la cuenca de México, la cual como unidad de estudio, es resultado de miles de años de evolución geológica y biológica, así como producto de una continua devastación provocada por la actividad humana.

Se puede asegurar que la gran tarea que se propusieron los autores, el estudio de la cuenca de México y sus problemas ambientales frente a la sustentabilidad, fue enriquecedora. Esto fue posible debido en gran medida a la perspectiva multidisciplinaria empleada, sin la cual el conocimiento del proceso histórico ambiental y actual sería imposible.

Es importante destacar que esta obra está precedida por dos magníficos, cuanto sintomáticos prólogos que muestran la enorme fragilidad y vulnerabilidad de la ciudad de México, que envuelve a la cuestión urbana en un nudo de complicaciones ambientales cuyo origen se encuentra en una ruptura de los ecosistemas naturales y las necesidades de la población; aunque algunos de estos daños aún se podrían reducir y otros revertirse si se contara con los recursos necesarios y políticas más efectivas.

En consecuencia, las políticas ambientales deben corresponder a las políticas económicas en general y éstas fundarse en el objetivo de alcanzar la compatibilidad de la economía urbana con los procesos ecológicos. Y, sobre todo, se debe considerar la participación ciudadana en el marco de la reapropiación social del ambiente, como el principal resorte que conduzca a un desarrollo urbano sustentable.

En el prólogo a la primera edición en inglés, Kasperson et al. describen los procesos de hiperurbanización, sus impactos y las políticas ambientales aplicadas, destacando el riesgo total am- 
biental de la ZMCM: "ambiente en riesgo, claramente encaminado a extremos críticos” (p. 15), lo cual constituye de por sí un auténtico laboratorio (Sarukhán, p. 11) para el análisis de los impactos que acarrea una urbanización desmedida. Sin embargo, las políticas ambientales aplicadas y sus resultados "señalan que aún puede detenerse la marcha hacia la situación crítica [...] pero, ¿están preparados para resistir lo inesperado (pp. 19-20).

Por su parte, en el prólogo a la edición en español, el doctor José Sarukhán se pregunta: ¿Qué tanto se ha avanzado desde el año 2000 al 2006, en relación con la previsión de Kasperson et al. acerca de la implosión de la degradación ambiental en la ciudad de México? La respuesta se la deja al lector.

De entrada, Ezcurra et al. consideran que la megalópolis "puede constituir el preludio de una gran catástrofe ecológica que en el futuro conducirá, para unos, a la descentralización forzada de la cuenca y, para otros, el problema ambiental deberá resolverse mediante el desarrollo tecnológico" (p. 26). También afirman que la ciudad y la cuenca de México "plantean una prueba a la sustentabilidad y a los riesgos ambientales que amenazan a sus pobladores" (p. 28).

De acuerdo con la metodología empleada se entiende el problema ambiental como un producto histórico que ha llevado a la situación actual, y se aplica un enfoque de Estado-presión-respuesta que se expresa en la organización y orden de los capítulos.

El origen de la ZMCM se remonta a una fascinante historia (ambiental) como la de la misma ciudad de México. De esta manera (capítulo primero), los autores se remontan a los orígenes y desarrollo histórico de la ciudad y muestran cómo estaba ligada a sus condiciones naturales y a un manejo adecuado (por ejemplo, las chinampas), lo que tampoco excluyó la sobreexplotación de los ecosistemas (donde destaca el caso de Teotihuacán); aunque no se compara con la degradación ambiental resultado de su evolución moderna.

La ciudad ha sido testigo de innumerables perturbaciones ambientales que la marcaron para siempre, como la lejana erupción del Xitle, las persistentes y trágicas inundaciones, los más recientes devastadores terremotos, como el de 1985, e incendios.

En su devenir, la ciudad de México continúa su expansión hasta el siglo XIX, pero no es sino hasta el siglo Xx, en las décadas de los cincuenta y sesenta, que rompe su unidad territorial originaria para abarcar áreas cada vez mayores y lejanas conformando una auténtica megalópolis, sometida a la anarquía de los pro- 
cesos de urbanización desmedida a partir de su centro (característica de los países en desarrollo).

Es también la historia de una extrema concentración de poder tanto económico como político, así como militar, religioso, etc., lo que da cuenta del dominio sobre la provincia (pasando México, todo es Cuautitlán), imponiéndose sobre regiones y comunidades rurales y urbanas de su cada vez más vasta periferia.

En el capítulo segundo se hace un balance de la situación socioeconómica de la cuenca. La preponderancia económica de la ciudad es fuente de enormes desequilibrios y un pretexto para mantener sus ventajas. Y si bien el proceso de descentralización ha avanzado en todo el país, éste no ha sido suficiente como para modificar el estado de cosas aún favorable, desde luego muy injustamente, a la ZMCM.

Se encuentra con que los procesos de metropolización han llevado a definir un área que incluye un centro y tres anillos metropolitanos, donde el crecimiento y la distribución poblacional muestran diferencias marcadas (p. 78). El centro se ha despoblado, no así los anillos donde se intercala la pobreza en distinto grado. Estos procesos describen un modelo caracterizado por la extrema desigualdad social, en el contexto de una urbanización que no ha respetado nada. Además, se avizora que el futuro desarrollo territorial incluye varios centros urbanos con un núcleo central (p. 90), en irremediable expansión hacia el norte, este y oeste.

De esa manera, el resultado ha sido la ampliación del área urbana que se reducía, de ser una mera fracción de la entidad federativa (D. F.), a la configuración de la ZMCM que abarca las 16 delegaciones del D. F., alrededor de 50 municipios del Estado de México y uno de Hidalgo; y para alimentarla en su sed insaciable, es necesario importar agua proveniente de las cuencas de los ríos Lerma-Santiago, Sistema Cutzamala (y se prevé que muy pronto habrá que incorporar la cuenca del río Amacuzac). Por su parte, la cuenca de México abarca 86 municipios y delegaciones del D. F. y de los estados de México, Hidalgo, Puebla y Tlaxcala (p. 89).

Una característica central del desarrollo urbano efectuado es la transición del D. F., en tanto ciudad centrada en la actividad industrial, a una donde prevalecen las actividades de servicios, que en el 2000 aglutinaron a $72 \%$ de la población empleada; a la par que se mantiene el predominio económico de la ciudad sobre el resto del país, pues concentra $21 \%$ de la fuerza de trabajo industrial a nivel nacional (Nuevo León 8\% y Jalisco 6\%). 
El modelo en funciones se puede caracterizar principalmente a través de dos formas. En la primera, se cuenta con toda una red de desarrollo inmobiliario moderno, servicios e infraestructura, mientras que la segunda se caracteriza por falta de empleo, servicios (sobre todo agua potable, drenaje y transporte) e insuficiencia de vivienda (mientras que la violencia e inseguridad está en todas partes).

El resultado (capítulo tercero) ha sido la destrucción de los ecosistemas y la subyugación de áreas rurales cada vez más lejanas (p. 106); además de las pérdidas ocasionadas por el excesivo tiempo de transportación que emplea la población (sobre todo en la parte oriental) a sus centros de trabajo (situados en su mayoría en la parte norte) y el retorno a sus hogares. Todo ello hace menos viable la economía urbana capitalina, que además ha vivido la emigración de la industria a otros sitios; aunque todavía conserva altos niveles de competitividad en al ámbito nacional.

Los cambios recientes en la situación ambiental de la cuenca incluyen, además, el impacto de los patrones de urbanización, principalmente en los recursos hídricos: demanda, utilización y recarga de agua (con énfasis en la baja recarga del acuífero y las fugas), así como los hundimientos persistentes, baja calidad del agua y sistema de drenaje deficiente; en los crecientes desechos (líquidos y sólidos); así como en la contaminación atmosférica (pp. 107-158).

En el capítulo cuarto se describen las fuerzas motrices del cambio ambiental que incluyen el cambio poblacional, las políticas gubernamentales, la distribución de la riqueza y los recursos (donde se advierte acerca de las tendencias a la pobreza y desigualdad social, así como del auge de la economía informal) e igualmente la concentración de la capacidad tecnológica (p. 160). El resultado es que

\footnotetext{
A pesar de que las tasas de crecimiento de la cuenca tienden a disminuir, las presiones a corto plazo para ocupar terrenos periféricos sin servicios se mantendrán y actuarán como una fuerza motriz importante para la expansión urbana y los procesos de conurbanización: la creciente polarización de ingresos (y del mercado laboral) convierte a estos terrenos marginales en una alternativa posible para los más pobres entre los pobres, aunque la periferia represente un sitio cada vez más alejado de los lugares potenciales de trabajo, un deficiente suministro de servicios, una mala calidad ambiental y costos altos de transporte (p. 178).
} 
A lo largo del libro destaca la presencia de lo que los autores denominan dobles subsidios (ecológicos y económicos), generando dos graves conflictos: 1) el que es producto de la destrucción de los ecosistemas y 2) el conflicto derivado de la subordinación económica de la periferia al centro, que no ha eliminado las ventajas que la ciudad da a "migrantes recientes que han llegado a la cuenca desde el México rural en busca de los bienes y servicios que ésta parece prometer" (p. 184) y que sólo se revierte por la creciente emigración a Estados Unidos. Dichos subsidios propician que la megaciudad siga creciendo incesantemente.

Estos dos conflictos han hecho sentir que la vulnerabilidad urbana (capítulo quinto) está ligada a las perspectivas de la ciu$\mathrm{dad}$, las cuales tienen que ver con una ciudad sobrepoblada que enfrentará la escasez de vegetación y espacios abiertos; en un contexto de menor disponibilidad e insuficiente reutilización del recurso hídrico, excesivo tráfico vehicular, graves problemas de contaminación, enfermedades, etcétera.

En el capítulo sexto se destaca que la respuesta al problema ambiental está ligada a la construcción de una conciencia ambiental, la cual incluye: las tendencias de las instituciones gubernamentales, la evolución de las políticas, el cambio de paradigma y se destacan nuevas herramientas económicas y políticas. Aparece así la sustentabilidad ambiental como una importante preocupación política; y luego se señala lo difícil de las perspectivas para las políticas públicas. Finalmente, se explican las tendencias de las políticas no gubernamentales, el activismo ecológico y la conformación de redes, como medios para enfrentar la degradación ambiental en la ciudad.

En las conclusiones se afirma que

\begin{abstract}
Aunque el crecimiento de la población está disminuyendo, y muchos jóvenes de clase media están emigrando a otras ciudades en busca de una mejor calidad de vida, la migración de campesinos provenientes de las regiones rurales empobrecidas hacia la megalópolis continúa, y la ciudad se sigue extendiendo sobre bosques y campos. Además el consumo de combustibles fósiles, la cantidad de automóviles, la sustitución de bosques por áreas urbanas y el bombeo de agua subterránea de un acuífero críticamente disminuido siguen aumentando a una tasa frecuentemente más alta que el propio crecimiento poblacional (pp. 241-242).
\end{abstract}

De ahí la necesidad, señalan, de una fuerte política de descentralización, eliminación de los subsidios, aumento de la conciencia sobre la magnitud del problema, así como la vinculación con 
el modelo económico y político a desarrollarse en el siglo XxI (pp. 242-243).

La historia de la cuenca es una de crecimiento, colapso y renacimiento cultural. Los conflictos crecientes sobre el uso del agua, la severa contaminación del aire, la inadecuada eliminación de desechos, los problemas de salud relacionados con el ambiente y la merma de los recursos naturales son asuntos comunes a la mayoría de las megalópolis de los países en vías de desarrollo. La cuenca de México es un laboratorio donde se prueban muchos de los procesos que provocan cambios en las poblaciones, en los recursos naturales y el uso del suelo en los países menos desarrollados. Este laboratorio proporciona escenarios fascinantes y terribles sobre lo que el futuro podría deparar a muchas de las megalópolis de América Latina y el Tercer Mundo (p. 244).

Los autores mantienen un "optimismo cauto que les permite vislumbrar resquicios de una recuperación que puede lograrse a través de las políticas ambientales recientes, los esfuerzos coordinados de las organizaciones no gubernamentales, las tecnologías innovadoras y una ciudadanía con capacidad de recuperación” (Kasperson et al., p. 17).

\section{Aportaciones principales}

Se puede decir con certeza que los esfuerzos desarrollados a lo largo de esta investigación resultaron bastante exitosos; y por todo el panorama crítico ofrecido, el texto es invaluable para cualquier estudioso e interesado en este gran tema como es la ZMCM.

El resultado es que la cuenca abastece cada vez menos agua a la población de la megaciudad y donde aumenta aceleradamente la demanda ficticia de ella (fugas, derroche, crecimiento urbano), mientras que su capacidad que sólo es para 8.5 millones de personas se alcanzó en el año 1964 (p. 117).

La megalópolis de la ciudad de México no puede entenderse si su viabilidad no se enmarca en el estudio de la cuenca de México. Ésta es sin duda la principal aportación de los autores, que por lo demás viene a confirmar la teoría, puesto que la destrucción de la naturaleza es directamente proporcional a un modelo insustentable. De ahí que este libro proporcione un marco referencial y analítico que es de suma importancia para entender, y sobre todo detener, los rumbos de la degradación urbana y modificarlos en una dirección opuesta.

Este modelo urbano conlleva dos claros límites bien destacados en el libro. El primero tiene que ver con las barreras natura- 
les: desde la presencia de zonas de minas, barrancas y fallas geológicas hasta la crisis del agua, falta de áreas verdes (aunque en el D. F. 59\% del territorio es rural, pero muy degradado). Este límite implica un deterioro en la calidad ambiental. Mientras que el límite social está relacionado con una baja calidad de vida (desigualdad social, pobreza, enfermedades etcétera).

En suma, una reducida extensión territorial es capaz de provocar enormes desequilibrios a su alrededor, tal es el caso de la disminución del nivel del lago de Chapala (aunque aunado a otras causas). De esa forma, la ciudad toma recursos frescos de su periferia y los devuelve en forma de desechos líquidos y sólidos (Hidalgo y Estado de México) contaminados.

\section{Insuficiencias y limitaciones}

No obstante, se pueden encontrar algunas debilidades en el libro. Quizá la mayor sea la falta de contundencia para plantear soluciones a la problemática estudiada. De esta forma, no se mencionan las características del modelo alternativo (que no puede limitarse a la descentralización y eliminación de subsidios, p. 243), con el cual se articularían las políticas ambientales.

Asimismo, se le da más importancia a las políticas gubernamentales que a la expansión y consolidación de las redes ambientales para la solución de la problemática estudiada, la cual no se restringe a la lucha contra la contaminación (p. 216); mientras que no se le atribuye suficiente trascendencia a la organización y movilización social (que fue fundamental como reacción al terremoto de 1985).

Lo anterior está asociado a la metodología empleada. En ese sentido, se pudieron plantear aquellos aspectos que conciernen a la intersección de la economía y la ecología (por ejemplo, las conexiones entre la naturaleza y la agricultura, industria y servicios) y no analizarlos de manera separada. Así, el primer capítulo se refiere a la historia ambiental, el segundo a la economía, el tercero, cuarto y quinto capítulos están ligados a los impactos de la economía sobre el ambiente ecológico y el capítulo sexto a las respuestas al problema ambiental. Sin embargo, no hay un apartado donde se integren la ecología y la economía urbanas.

Por otro lado, ante tan abrumadora presencia de cifras, éstas resultan no muy precisas cuando se ofrecen diversas estimaciones a partir de estadísticas provenientes de distintas fuentes. Aunque ello se justifica por la relativa ausencia de información 
oficial fidedigna y por el hecho de que las estadísticas no se presentan como relativas a la ZMCM en cuanto tal, sino al D. F., estados de la Federación o la ciudad de México.

Además, es notoria la ausencia de un capítulo dedicado al manejo de conceptos básicos como ambiente, sustentabilidad, desarrollo urbano, etc. Ello hubiese permitido un texto mucho más rico de lo que es, consolidando los puentes entre las ciencias geofísicas, la ecología y las ciencias sociales. De esa forma, el manejo teórico resultó insuficiente y en ocasiones ambiguo, como en el caso del concepto mismo de ambiente, el cual pareciera reducido a lo ecológico por oposición a lo social (y puesto que lo social también es intrínseco al ambiente); y en consecuencia, con el de sustentabilidad ambiental. Todo ello lleva a cierta confusión en el lector.

Un aspecto importante a considerar es la falta de una mayor explicación de la economía mexicana, la cual no se puede entender sin la comprensión del papel histórico y actual del campo mexicano. De hecho, cuando en las conclusiones se plantea la descentralización como una medida indispensable para resolver el problema ambiental (p. 243), ésta no se asocia para nada con la necesidad de impulsar un desarrollo rural que sea convergente con dicha descentralización. Y es que el desarrollo rural está asociado a los patrones de urbanización.

Así, la migración a la ZMCM no sólo se explica por los dobles subsidios, sino también por el modelo rural caracterizado por la exclusión y el abandono. De manera que un adecuado desarrollo rural ayudaría igual que la eliminación de tales subsidios urbanos a un reordenamiento de la población, desde luego junto con el territorial.

De lo señalado se desprende además que un elemento enriquecedor para el análisis de las grandes ciudades es el papel de la producción agropecuaria, agroalimentaria específicamente (véase, por ejemplo, la iniciativa de la ONU denominada WEHAB, por sus siglas en inglés: Water, Energy, Health, Agriculture and Biodiversity, para cumplir con las Metas del Milenio, Johannesburgo, 2003). Y mientras que en el primer capítulo, relativo a la historia ambiental, se estudió la producción alimentaria local para entender la productividad ecológica de la cuenca, después este aspecto ya no se trató. Pero ello también sigue siendo fundamental en la sociedad actual, ya que el suministro de alimentos no puede dejarse simplemente a la importación de otras regiones, aparte del hecho de que su producción implica una precondición energética esen- 
cial (energía calorífica) para la población; así como una reducción en el consumo de energía, con el consecuente ahorro de dinero. El desaprovechamiento de los recursos agrícolas de la región no se debe entender como algo que está ocurriendo inevitablemente, ya que se trata de un hecho que debiera corregirse (mediante el impulso de los mercados agrícolas, agroindustriales y agroalimentarios), pues la sustentabilidad alimentaria es parte de la sustentabilidad en general, y urbana en particular. Además esto se relaciona con los programas de agricultura urbana impulsados por la ONU (y en el marco de la nueva ruralidad). Por lo tanto, este aspecto es parte de la solución a la crisis ambiental.

La discusión sobre el desarrollo urbano es una falta importante, ya que sin tener claridad en el modelo de sustentabilidad urbana apropiado que se puede ofrecer para la ciudad de México, la solución a esta crisis no será posible.

Un último punto tiene que ver con los subsidios económicos que otorga la gran ciudad. Éstos en sí no son buenos ni malos. Está claro que en muchos casos los subsidios se deben seguir dando cuando, por ejemplo, no hay otra forma (el mercado no lo puede hacer) de satisfacer necesidades sociales (o bien de atraer capitales frescos para la ciudad). Sin embargo, los subsidios siguen siendo un imán para los inmigrantes.

Pese a las dificultades señaladas -lo que sería exigir a los autores demasiado después de los resultados, hallazgos y aportaciones presentados en el libro-, el balance es altamente positivo. Hay que reconocer que, finalmente, el avance del conocimiento y la necesaria intervención social para salir de la crisis ambiental -agravada por el calentamiento global- y poder transitar así a otro escenario: la sustentabilidad urbana, inevitablemente es producto de un esfuerzo colectivo más amplio, al cual los autores contribuyeron adecuadamente y en gran medida.

\section{Conclusión}

La participación ciudadana como eje de la transformación en el entorno urbano hacia otro cualitativamente diferente resulta esencial en la transición hacia ese nuevo ambiente. Esto es indispensable para enfrentar el dilema de supervivencia: megalópolis o red de ciudades verdes.

Para avanzar hacia la última opción, es necesaria una actualización de las leyes ambientales bajo una perspectiva que abarque el conjunto del problema socioambiental. Es necesaria, pues, 
una mayor visión, un enfoque de prevención y atacar el problema no nada más como un ejercicio de recaudación fiscal (el que contamina paga). Es indispensable impulsar una ley y políticas públicas que no sólo afiancen la disminución y prevención de la contaminación (como la Ley General del Equilibrio Ecológico y Protección al Ambiente), sino que a la vez permitan avanzar hacia un desarrollo sustentable como modelo económico en todo el territorio nacional. Para ello es necesario conocer, como lo ofrecen los autores, las causas y efectos de la degradación ambiental, paradigmáticos en la ZMCM. De ahí la gran importancia de este texto, que si bien es rigurosamente científico, también es fácil de entender para el público en general.

Por estas razones invitamos a los lectores de la revista Economía, Sociedad y Territorio, ante la conflictividad socioambiental de la ciudad de México, a no resistirse a leer, y sobre todo estudiar, éste que por mucho tiempo será un libro actual: La cuenca de México. Aspectos ambientales críticos y sustentabilidad, que el Fondo de Cultura Económica ha tenido el tino de publicar en el año 2006, aunque sea un poco tarde.

Guillermo Torres-CARRAL Universidad Autónoma Chapingo Correo-e: gatocarr@hotmail.com

Recibido: 3 de agosto de 2007. Aceptado: 14 de agosto de 2007.

Guillermo Torres Carral. Es doctor en ciencias agrícolas por la Universidad Agrícola de Varsovia, Polonia (1987). Realizó sus estudios de maestría en economía agrícola y política agraria en la misma universidad (1984). Asimismo, es egresado de la Facultad de Economía de la Universidad Nacional Autónoma de México (UNAM) (1977). Se desempeña como profesor-investigador de tiempo completo en el doctorado de Ciencias Agrarias, así como en el doctorado en Educación Agrícola Superior, en el departamento de Sociología Rural de la Universidad Autónoma Chapingo. Sus líneas de investigación son: economía ecológica, alternativas del minifundio mexicano, nueva ruralidad y desarrollo sustentable en México. Entre sus publicaciones más recientes se encuentran: Introducción a la economía política ecológica, Plaza y Valdés-UAch, México (2001); Civilización, ruralidad y ambiente, 
Plaza y Valdés-uAch, México (2003); en coautoría, Agricultura ecológica y reconstrucción social, UAch, México (2004); Poscivilización: guerra y ruralidad, Plaza y Valdés-UAch, México (2006); "El campo mexicano: los caminos del desarrollo rural sustentable", Revista Agro Nuevo, año 2, 15, Secretaría de la Reforma Agraria, México (2006); "El pago por servicios ambientales y las comunidades indígenas", Revista RA XIMHAI, año 2, 1, México (2006). 